\title{
Experimental Analysis of Linear Induction Motor under Variable Voltage Variable Frequency (VVVF) Power Supply
}

\author{
Prasenjit D. Wakode ${ }^{1}$, Mohd Tariq², Tapas Kumar Bhattacharya ${ }^{3}$ \\ 1, 2, 3 Department of Electrical Engineering, Indian Institute of Technology (IIT), Kharagpur, India \\ ${ }^{1}$ Presently at, Tool \& Gauge Division (TGM), Bharat Heavy Electricals Limited, Bhopal, India \\ ${ }^{2}$ Presently at, School of Electrical and Electronic Engineering, Nanyang Technological University, \\ Singapore
}

\begin{abstract}
This paper presents the complete analysis of Linear Induction Motor (LIM) under VVVF. The complete variation of LIM air gap flux under 'blocked Linor' condition and starting force is analyzed and presented when LIM is given VVVF supply. The analysis of this data is important in further understanding of the equivalent circuit parameters of LIM and to study the magnetic circuit of LIM. The variation of these parameters is important to know the LIM response at different frequencies. The simulation and application of different control strategies such as vector control thus becomes quite easy to apply and understand motor's response under such strategy of control.
\end{abstract}

Keywords: Linear Induction Motor, Variable Voltage Variable Frequency, Experimental, air gap flux density, blocked linor.

\section{Introduction}

A linear motor can be obtained by cutting a rotary motor along it's radius from the center axis of the shaft to the external surface of the stator core and unrolling the cut motor to get a flat construction of (previously) annular stator and cylindrical rotor [1].

Since the stator and rotor both have finite diameters, hence their lengths in linear version will also be finite and hence machine with mere such a construction will obviously not be of practical use. This is because as any of the part (stator or rotor) start moving it goes slowly out of the influence of the other part and stops moving after some time when it comes completely out of influence of the other part. Hence it is necessary that either both the members be infinitely long-which is again not practical or at least one of the two members be very long and the other one is of some finite length [2-3].

The LIMs performance is affected by the conductor reactance, resistance and the construction of the secondary structure [4]. In the linear structure, the moving part which may or may not be the rotor of the induction motor is called as the 'linor'. In general terms, the part which we excite by electrical supply to windings is called as the 'primary' and the other part is called as the 'secondary'. The LIM has many merits in comparison to the rotary induction motor (RIM): higher ability to exert thrust on the secondary without mechanical contacts, greater acceleration or deceleration, less wear of the wheels etc. [5].The main advantage of LIM is its open magnetic structure gives us access to its air gap magnetic field very easily and measurements of this field can be carried out with search coil. Also the starting force measurements are easy to carry out with simple instruments such as spring balance placed horizontally and one end attached to a rigid support.

Recently the finite element modeling (FEM) approach has gained greater importance in modeling of LIM [6]. Many research has been done considering attraction force and transverse edge effect of LIM [7]. 
LIM finds tremendous application in transportation. Many countries has come up with transport network based on LIM [8-10]. Other application of induction motor beside transportation are in railway engines,

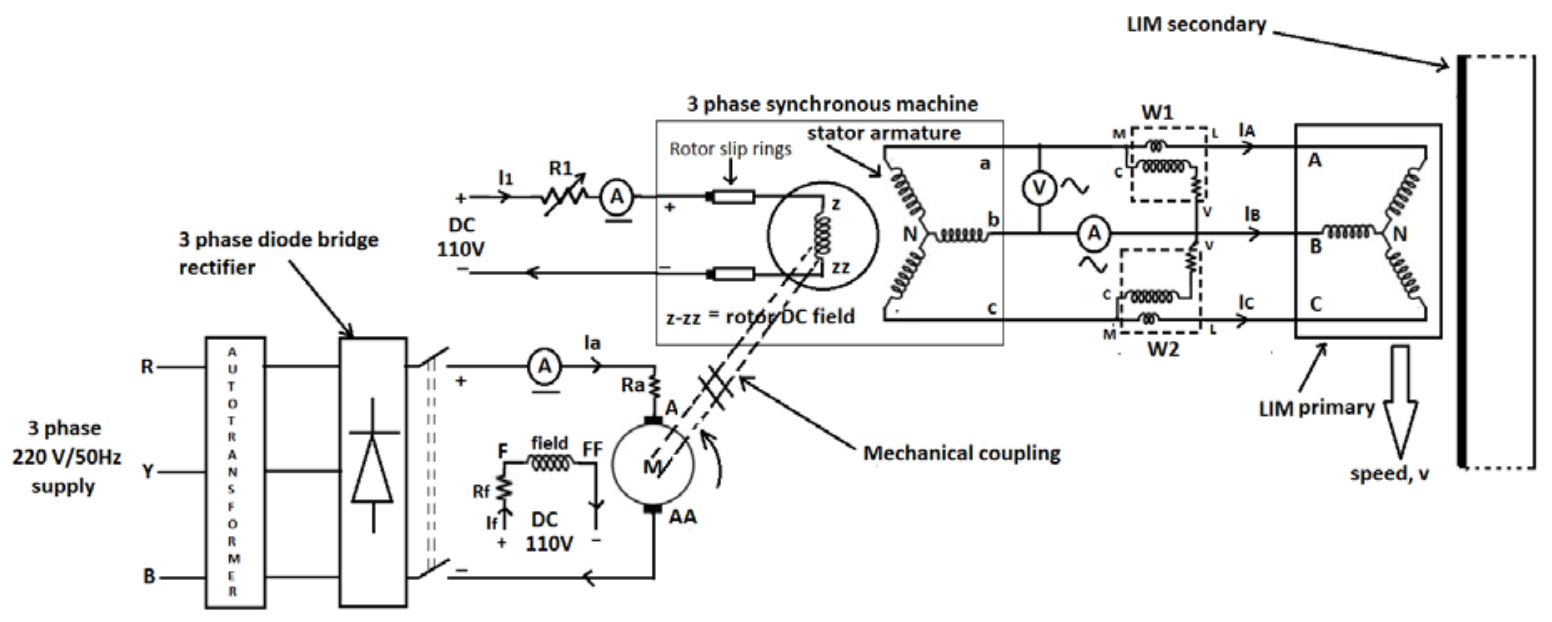

Fig. 1 Schematic connection diagram to obtain VVVF supply to LIM primary

self-excited induction generators for distributed generation in rural areas [11-13], etc.

This paper is organized as follows: Section 2 describes the experimental setup and procedure to obtain the VVVF supply and the methods used to measure the air gap flux density and starting thrust of LIM under 'blocked linor' condition. The experimental values of flux density and starting thrust under VVVF supply are plotted in section 3. Observations and conclusions from these plots are stated in section 4.

\section{The experimental set-up to obtain VVVF supply:}

The schematic connection diagram of the supply arrangement which is used to obtain VVVF supply for LIM testing is shown in figure 1.

In the above figure the mechanically coupled arrangement of a DC machine- synchronous machine set up has been done. The DC machine used was of the separately excited type. The field terminals of DC machine are marked as F-FF and the armature terminal are marked as A-AA as shown. $R_{f}$ and $R_{a}$ are the internal winding resistances of the DC machine field winding and armature winding respectively.

In the arrangement used for LIM testing, rated constant voltage was given to field winding throughout the testing. The armature was given DC supply through a 3 phase diode bridge rectifier.The AC input to bridge rectifier was given by means of a variac (or autotransformer) so that we can have smooth control over the armature voltage. Speed of the DC machine was varied by means of varying the bridge rectifier output through autotransformer.

An ammeter was connected in series with the armature so that the armature current can be observed and it can be maintained within the safe limit set up by rated armature current limit of DC motor.

The synchronous machine rotor DC field voltage can be varied by means of varying the variable resistance R1 connected in series with the DC rotor field. The rheostat for R1 is of appropriate current rating. The alternator's 3 phase armature output was given to LIM which is the regulated VVVF supply.

The ammeter connected to one of the armature phases will give the LIM phase current 'Iph' and also the alternator armature current can be observed so as to maintain it within it's safe limit specified by its rated value.

The LIM line voltage $(\sqrt{3} \mathrm{Vph})$ is obtained by voltmeter connected in parallel between any of the two phases as shown in Fig. (1). The real power input to LIM is measured by means of 'two wattmeter method'.

For the power factor of $\cos (\varnothing)$, 
3 phase Power input to LIM = W1+W2 = 3.Vph.Iph.cos $(\varnothing)$ (watts)

i. Rating of different components:

a) DC machine specifications:

Armature rating and specification: $3.75 \mathrm{BHp}, 110 \mathrm{~V}, 32.6 \mathrm{~A}, 1200 \mathrm{rpm}, \mathrm{Ra}=1 \Omega$

Field ratings: $110 \mathrm{~V}, 1.8 \mathrm{~A}, \mathrm{R}_{\mathrm{f}}=61 \Omega$

b) Synchronous machine specifications:

Stator armature ratings: The stator armature has two sets of 3 phase output terminals which can be used at two different frequencies viz. $50 \mathrm{~Hz}$ and $60 \mathrm{~Hz}$.The voltage and current ratings are shown in table 1 for these two frequencies:

Table 1: The voltage and current ratings at two frequencies.

\begin{tabular}{cccccc}
\hline $\begin{array}{c}\text { Frequency } \\
\text { F (Hz) }\end{array}$ & $\begin{array}{c}\text { Output, } \\
\text { (KVA) }\end{array}$ & $\begin{array}{c}\text { Line voltage } \\
\text { (V) }\end{array}$ & $\begin{array}{c}\text { Line current } \\
\text { (A) }\end{array}$ & Speed (rpm) & No of poles, $\mathbf{P}$ \\
\hline 50 & 3.0 & 130 & 13.3 & 1000 & 6 \\
60 & 3.0 & 125 & 13.9 & 1200 & 6 \\
\hline \hline
\end{tabular}

The per phase armature resistance $=0.35 \Omega$

DC rotor field ratings: $110 \mathrm{~V}$, field DC winding resistance $=10 \Omega$

LIM specifications: 3 phase, $50 \mathrm{~Hz}, 1.5 \mathrm{~kW}, 110 \mathrm{~V}$, Pole pitch=9.65 cm

\section{ii. Method used for obtaining VVVF supply}

Principle: The rotating DC voltage supplied rotor's field with speed $\mathrm{Nr}$ rpm induces voltage in the stator armature of synchronous machine. The magnitude of this induced voltage depends on the speed of rotation $\mathrm{Nr}$ rpm of synchronous machine and also the air gap flux produced by the DC supplied rotor i.e. the amount of current in the DC rotor winding. The frequency of the AC induced voltage depends on the rotor speed $\mathrm{Nr}$ of alternator.

Control Mechanism: To change the frequency of the output voltage, we increase the speed of the DC motor which acts as a prime mover for the alternator. The speed of DC motor is varied by 'armature voltage control' method by varying armature voltage using autotransformer. The main problem with this is that increasing the DC motor speed will increase the frequency as well as the magnitude of the alternator output voltage. frequency.

So the alternator rotor DC field is needed to be reduced so as to obtain the same voltage at higher

If, an alternator with $\mathrm{P}$ no of poles is rotating at a speed of $\mathrm{Nr}$ rpm, then output frequency $\mathrm{f}(\mathrm{Hz})$ of the armature voltage is given by,

$\mathrm{f}=\frac{\mathrm{P} \cdot \mathrm{N}_{\mathrm{r}}}{120} \mathrm{~Hz}$

In the air gap, constant flux $\varphi \mathrm{Wb}$ is set up by the DC field of rotor at standstill. If the rotor is rotating then, the flux $\varphi$ linked with each phase is actually a time varying quantity $\varphi(\mathrm{t})$ as viewed from the stator, and is given by 


$$
\varphi(t)=\varphi_{\max } \cdot \cos (\omega . \mathrm{t})
$$

where $\omega=2 \pi f \mathrm{rad} / \mathrm{sec}$.

If the output armature voltage has frequency $\mathrm{f} \mathrm{Hz}$, then the instantaneous induced voltage in each phase of the armature having per phase no. of turns Tph and winding factor of $\mathrm{Kw}$ is :

$$
\begin{aligned}
& \mathrm{E}_{\text {ph.a }}(\mathrm{t})=\omega \cdot \mathrm{Tph} \cdot \varphi_{\mathrm{max}} \cdot \cos (\omega \cdot \mathrm{t}) \cdot \mathrm{Kw} \text { (volts) } \quad \text { (A phase induced voltage) } \\
& E_{\text {phb }}(t)=\omega \cdot T \text { ph. } \varphi_{\max } \cdot \cos \left(\omega \cdot t-\frac{2 \pi}{3}\right) \cdot K w \text { (volts). (B phase induced voltage) } \\
& \left.E_{\text {ph.c }}(t)=\omega \cdot T \text { ph. } \varphi_{\max } \cdot \cos \left(\omega \cdot t+\frac{2 \pi}{3}\right) \cdot K w \text { (volts }\right) \quad(C \text { phase induced voltage })
\end{aligned}
$$

As the armature windings are distributed at a spatial displacement of $120^{\circ}$ in space w.r.t. each other, hence the induced voltages in each phase will be $120^{\circ}$ phase shifted from one another as described by Eq. (4) to (6).

Hence, we have to always adjust both $\varphi_{\max }$ (by adjusting the DC current of the alternator rotor) and frequency ' $\mathrm{f}$ ' (by adjusting armature voltage of DC motor) at a time if we want to achieve same voltage at different frequencies or vice versa.

\section{iii. Advantages and disadvantages of this supply arrangement:}

a) Advantages:

- This arrangement is the ideal and easiest method to obtain a constant V/f supply at different frequencies. From Eq. (4) to (6), it can be observed that if the DC current of alternator DC field is kept constant i.e. if $\varphi_{\max }$ is kept constant then if we neglect stator leakage reactance, stator winding resistance voltage drop of alternator and primary winding resistance and leakage reactance voltage drops in LIM, then for LIM, the induced voltage to frequency i.e. Eph/ $\omega$ ratio is constant at different frequencies $\omega \mathrm{rad} / \mathrm{sec}$.

- This method is very rugged and robust method to obtain V/f as once the DC rotor current is adjusted at some value, then by just varying the autotransformer voltage, we achieve almost constant V/f across the load terminal at armature.

- More robust and easy to use than the PWM inverter.

\section{b) Disadvantages:}

- In running condition of alternator, as the load to armature increases, then the alternator speed reduces. To keep the alternator to run at same frequency irrespective of the armature terminals load variation, the alternator should be synchronized with the desired output frequency by some other alternator. This is somewhat tedious process because each time we want the different frequency then that time first of all that synchronization should be carried out and then the load is to be connected.

- This method is mostly suitable for the constant loads connected to the armature of alternator.

- The LIM at 'blocked linor' condition acts as a constant load and hence this method for obtaining VVVF supply suits best for such condition.

\section{iv) Testing of LIM prototype by this setup:}

In case of testing of LIM by using this setup, the measurement of starting thrust at 'blocked rotor' test can be easily carried out at different voltages and frequencies as load seen by armature of alternator is constant during 'blocked linor' condition. 


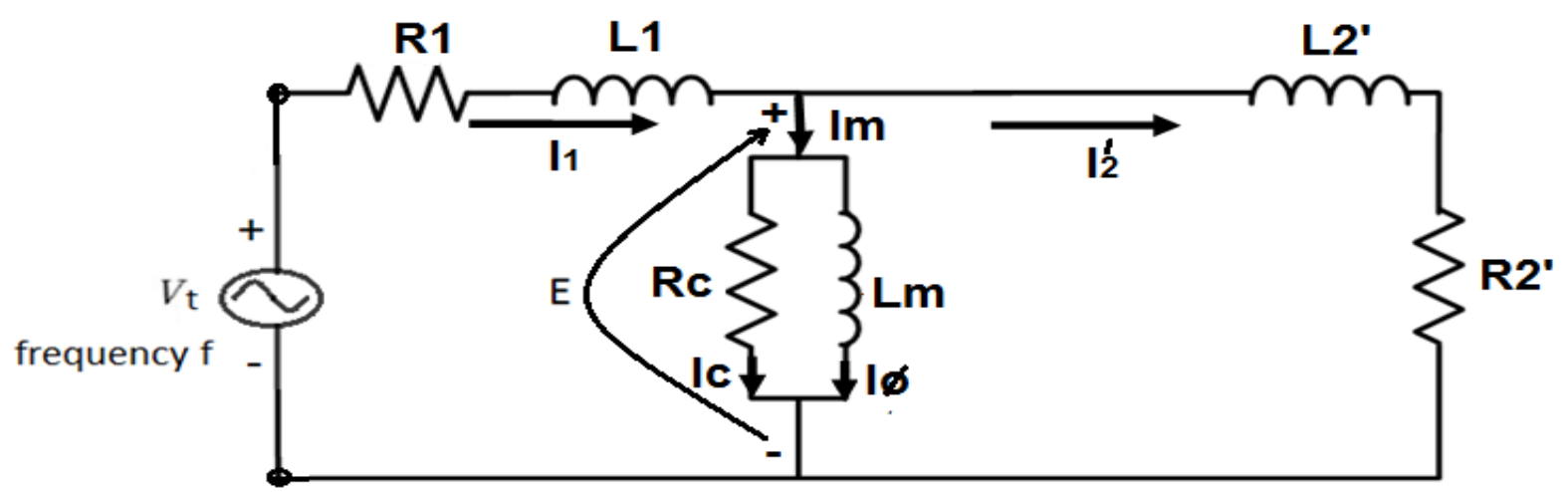

Fig. (2)Per phase exact equivalent ckt of LIM considering core losses at 'Blocked linor' condition

When LIM starts moving, the load seen by the alternator armature gradually reduces, hence because of this the speed of alternator $\mathrm{Nr}$ and hence armature supply frequency $\mathrm{f}$ increases and hence also the induced voltage as per Eq.(3) to (6). As the secondary length of the SS-LIM prototype used is around 4 meters which is a short distance for LIM, there is no appreciable increase in the supply frequency $f$ at running condition of LIM for this short distance of 4 metre. Hence, for the speed measurement on available setup of LIM prototype used, this method works sufficiently accurate.

To obtain voltages at low frequencies from alternator, the DC motor should be run at low speeds. At such low speeds if the DC field excitation of alternator is increased, the load to DC motor increases and it can increase to such extent that the DC motor armature current becomes more than the rated value i.e. DC motor can get overloaded if we try to get more magnitude of alternator output voltage at low frequencies. So there is a limitation on the maximum voltage that we can obtain from alternator at a given frequency. For operating voltages and currents of LIM at different frequencies, this setup is sufficient.

\section{Measurement}

\section{i) Measurement of air gap flux at VVVF supply under 'Blocked linor' condition:}

The flux density magnitude at a particular point on LIM primary is different than that of at other points at different locations because of edge effects, end effects, etc.

The following Fig. (3) shows the variation of maximum air gap flux Bmax vs LIM primary phase current at different supply frequencies. This air gap flux is measured by fixing the search coil at one specific particular point on the LIM primary iron core surface in the air gap.

As seen from fig (3) for the same primary phase current, the air gap flux density is reduced gradually. This is because, as we increase the supply frequency $\omega$, the leakage reactance $X_{L 1}=\omega L_{1}$ and hence the voltage drop across the primary leakage reactance becomes more and more prominent hence, the voltage across the magnetizing branch also goes on reducing and finally the magnetizing current is also reduced at increased frequencies as can be seen from the equivalent circuit of LIM as shown in Fig(2) .

Primary leakage reactance $=$ Iph. $\mathrm{X}_{\mathrm{L} 1}=\mathrm{Iph} . \omega \mathrm{L}_{1}$

We know that the magnetizing current is the main component of supply current which sets up the air gap magnetic flux. Hence, at increased frequencies, for the same applied voltage magnitude, as we have lesser magnetizing current, the air gap flux reduces.

\section{ii) Measurement of starting thrust by spring balance at VVVF supply:}

The fig. (5) shows the measurement of starting thrust (N) at 'blocked linor' condition by spring balance method vs primary phase current (A) at air gap $=0.7 \mathrm{~cm}$ air gap at different supply frequency . From fig.(4), it can be observed that at same supply current ,as the supply frequency is increased, the stating thrust gets gradually reduced .This is because the reduction of air gap flux as observed from fig.(3) . 


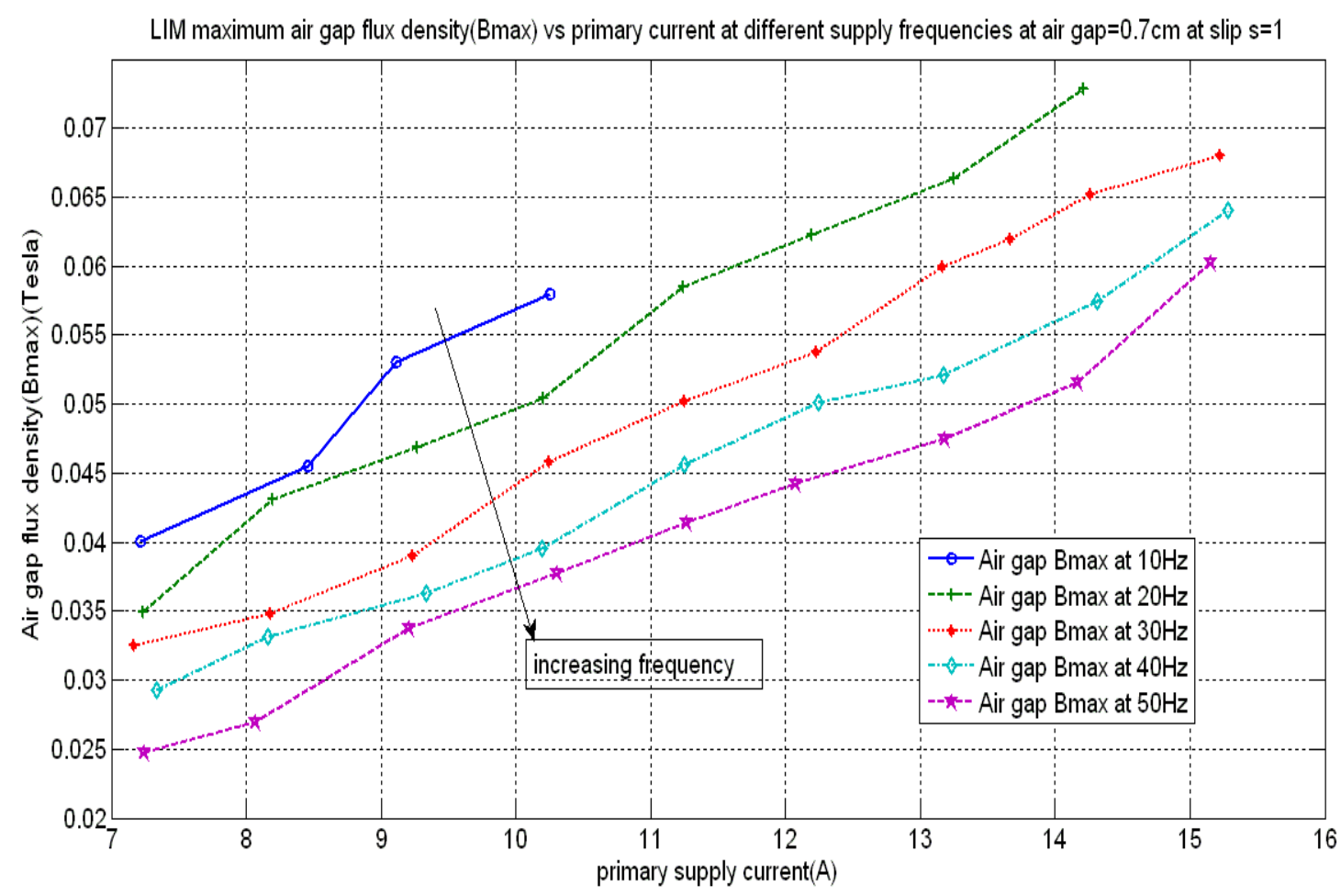

Fig (3). Maximum air gap flux density Y component Bmax (tesla) vs primary supply phase current (A) at different frequencies at 'blocked rotor' condition at $0.7 \mathrm{~cm}$ air gap

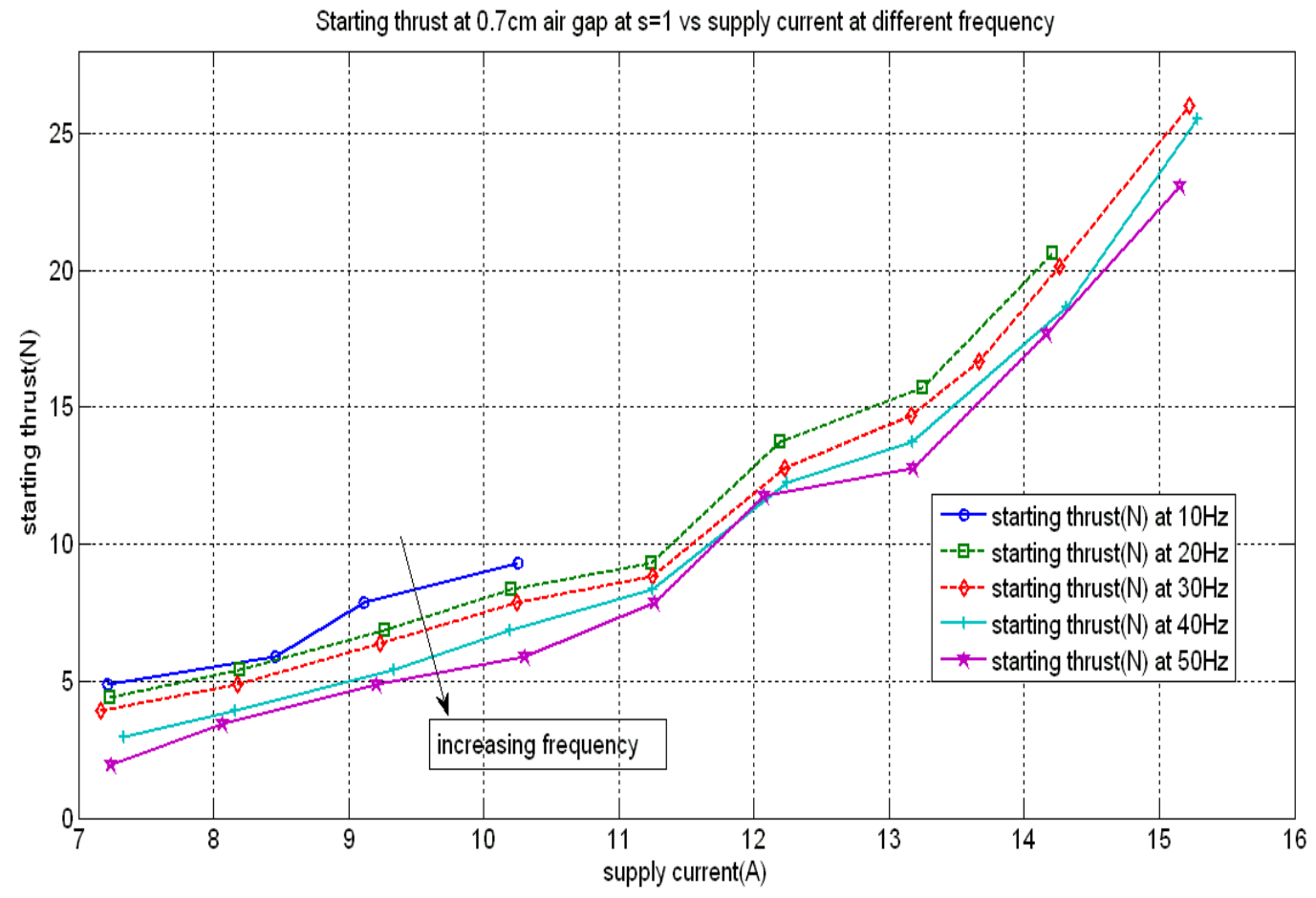

Fig (4). Starting thrust vs primary supply phase current (A) at different frequencies at 'blocked rotor' condition at $0.7 \mathrm{~cm}$ air gap

In phasor form, the force acted upon the LIM primary is, $\vec{F}=\overrightarrow{\mathrm{J}_{1}} \times \overrightarrow{\mathrm{B}}(\mathrm{N})$. 
As observed from Fig.(3), at different increasing frequencies, amplitude of $\vec{B}$ is reduced at same primary current Iph (i.e. at same primary linear current density amplitude $\overrightarrow{\mathrm{J}_{1}}$ ) at different increasing frequencies. Hence it is obvious that as per Eq. (8), the starting thrust $\vec{F}$ will decrease at constant $\overrightarrow{\mathrm{J}_{1}}$ and reduced air gap flux density $\overrightarrow{\mathrm{B}}$.

\section{Conclusion}

In this paper an experimental analysis of linear induction motor under variable voltage variable frequency (VVVF) power supply has been done. This analysis is required keeping in mind the tremendous application LIM is having in transport nowadays. Detail discussion of the experimental setup is given in the paper along with its merit and demerit. Maximum air gap flux density Y component Bmax (tesla) vs primary supply phase current (A) at different frequencies as well as starting thrust vs primary supply phase current (A) at different frequencies at 'blocked rotor' condition is presented and discussed for better understanding of the subject.

\section{Acknowledgements}

The work was done in the Electrical Machine laboratory of Electrical Engineering Department, Indian Institute of Technology (IIT), Kharagpur, India. The authors are thankful to the staff of the Electrical Machine laboratory.

\section{References}

1) K.Venkatratnam, "Special Electrical Machines” Universities Press India Pvt. Ltd. (2009),

2) Wei Xu, Jian Guo Zhu, Yongchang Zhang, Zixin Li, Yaohua Li, Yi Wang, Youguang Guo, Yongjian Li, "Equivalent Circuits for Single Sided Linear Induction Motors" ,IEEE Transactions On Industry Applications, Vol. 46, No. 6, ,Pages.2410-2422 November/December 2010

3) Wei Xu; Jianguo Zhu; Youguang Guo; Yi Wang; Yongchang Zhang; Longcheng Tan, "Equivalent circuits for single-sided linear induction motors," Energy Conversion Congress and Exposition, 2009. ECCE 2009. IEEE , vol., no., pp.1288,1295, 20-24 Sept. 2009

4) B.-J. Lee , D.-H. Koo and Y.-H. Cho "Investigation of linear induction motor according to secondary conductor structure", IEEE Trans. Magn., vol. 45, no. 6, pp.2839-2842 2009

5) Wei Xu, Jianguo Zhu, Longcheng Tan, Youguang Guo, Shuhong Wang, and Yi Wang, "Optimal design of a linear induction motor applied in transportation," in Proc. IEEE Int. Conf. Industry Technology, , pp. 791-795. Feb. 2009

6) S. C. Ahn , J. H. Lee and D. S. Hyun "Dynamic characteristic analysis of LIM using coupled FEM and control algorithm", IEEE Trans. Magn., vol. 36, no. 4, pp.1876 -1880 2000

7) A. K. Rathore and S. N. Mahendra "Simulation of secondary flux oriented control of linear induction motor considering attraction force and transverse edge effect", Proc. Int. Conf. Elect. Eng., pp.158 -1632003

8) R. Thornton, M. T. Thompson , B. M. Perreault and J. Fang "Linear motor powered transportation", Proc. IEEE, vol. 97, no. 11, pp.1754-1757 2009.

9) R. Hellinger and P. Mnich "Linear motor-powered transportation: History, present status, and future outlook", Proc. IEEE, vol. 97, no. 11, pp.1892 -1900 2009.

10) Wei $\mathrm{Xu}$, Yaohua Li, Guangsheng Sun, and Jinqi Ren, "Performance study on high power linear induction motor in transportation," in Proc. Int. Conf. Electrical Machines and Systems, pp.1025-1027, Oct. 2007.

11) M. Tariq and S. Yuvarajan. Modeling and Analysis of Self Excited Induction Generator with Electronic load controller supplying static loads. Canadian Journal on Electrical and Electronics Engineering, 4(1), pp.9-13, 2013.

12) M. Tariq, S. Yuvarajan, and P. Wakode. Digital Simulation of Electronic Load Controller with Reduced THD for Self-Excited Induction Generator. IUP Journal of Electrical and Electronics Engineering, 6(4), p.36, 2013.

13) M. Tariq and S. Yuvarajan, Simulink Based Modeling, Analysis and Simulation of Self Excited Induction Generator for Use in Remote Areas. IU-Journal of Electrical \& Electronics Engineering, 13(1), pp.1623-1628. 2013. 